ORIGINAL ARTICLE

\title{
Cytopathological Examination and Epidemiological Study of Cervicitis in Commercial Sex Workers (Csws) in Coal City (Enugu), Nigeria
}

\author{
Odigie Bolaji Efosa ${ }^{1,2}$, Achukwu Peter Uwadiegwu ${ }^{2}$
}

\section{ABSTRACT}

BACKGROUND: Illicit sexual behavior by commercial sex workers (CSW) may have a disproportionate impact on the reproductive health of a woman that often leads to cervicitis. This study aimed at examining the cytopathology, patterns, prevalence and burden of cervicitis in CSW in Enugu metropolis, Nigeria.

METHODS: Cervical smear was collected from the endocervix of about one hundred and eighteen (n=118) CSWs between November, 2014 and February, 2015 using the liquid-based cytology (LBC) method. Smears were processed and stained by the modified Papanicolaou method. Leftover samples were tested for sexually transmitted diseases, especially $N$. gonorrhea, and $C$. trachomatis using ligase chain reaction and nucleic acid amplification test. A randomized sampling design was used for data collection.

RESULTS: Cytopathological examination of cervicitis in CSWs showed a moderate infection, and moderately severe to chronic inflammatory cells. The epidemiological study revealed that acute cervicitis are predominant $7(5.9 \%)$ and $2(1.7 \%)$ are chronic cervicitis. The prevalence of CSWs living with cervicitis in Enugu, Nigeria (7.6\%), is significantly affected by age and working duration as CSWs. Also, Chlamydia trachomatis is the solely associated pathogen implicated in cervicitis group $(n=9)$. Candidiasis infection $(n=12)$ and $T$. vaginalis $(n=3)$ are observed in non-cervicitis group $(n=109)$ while the association between $C$. trachomatis and cervicitis infection is statistically significant $(P=0.0221)$.

CONCLUSIONS: Acute cervicitis was prevalent with a preponderance of 4:1 in CSWs in Enugu, Nigeria. C. trachomatis infection was the most prevalent etiologic agent of cervicitis in this study. Further molecular study of LBC smears from CSWs using PCR is strongly recommended.

KEYWORDS: Candidiasis, Cervicitis, cervical smear, Cervix, Chlamydia trachomatis and Cytopathology.

DOI: http://dx.doi.org/10.4314/ejhs.v25i3.5

\section{INTRODUCTION}

Globally, sex work takes place in a wide variety of settings, ranging from established, formal brothels to more informal venues such as bars, hotels, roadside truck stops or at home (1). Commercial sex is a risky activity of both acquiring and transmitting sexually transmitted diseases (STDs). It has a disproportionate impact on the reproductive health of women, often leading to cervicitis (2). In this context, cervicitis refers to inflammation of the uterine cervix by which the inflammation primarily affects the columnar epithelial cells of the endocervical glands (2). It can also influence the squamous epithelium of the ectocervix (2). Furthermore, cervicitis may be due to infectious or non-infectious etiology, and may

\footnotetext{
${ }^{1}$ Department of Medical Laboratory Science, School of Basic Medical Science, College of Medical Science, University of Benin, Nigeria

${ }^{2}$ Department of Medical Laboratory Science, Faculty of Health Science and Technology, College of Medicine, University of Nigeria, Nigeria

Corresponding Author: Odigie, B.E, Email: bolaji.odigie@uniben.edu
} 
be acute or chronic (3). Acute cervicitis is usually the a result of an infection (e.g., Chlamydia, gonorrhea) while chronic cervicitis has a noninfectious source $(2,3)$. Cervicitis appears to be associated with a significant increase in the risk of HIV-1 acquisition and shedding (4). Hence, CSW serves as a common source of infection $(5,6)$.

Recent studies have addressed the global estimates of CSW's population size (7). Commercial sex work could be one of the several risk factors for HIV (8), STI and Cervicitis in SubSaharan Africa $(2,9)$. Reviews are yet to provide a detailed information on social and behavioral aspects of CSWs in sub-Saharan Africa (9). The examination of the relationship between CSW's vulnerability to cervicitis acquisition and the prevailing structural and occupational context of her illicit business are limited in review (2). There are inevitable variations in the practice of a CSW within the operational region. Nonetheless, a clearer understanding of the pattern of life a CSW lives on the continent; may help to inform on the type of design and implementation necessary for the vulnerable group (10). A single specimen that could be used to screen for cytologic abnormalities, C. trachomatis, and $N$. gonorrhea would provide a simple way to accomplish multiple screening objectives simultaneously (11). By using LBC, there would be no need for multiple specimen collection kits or different procedures for sample processing (11). LBC sample is a single specimen with an added advantage of being preserved and available for additional DNA detection tests (such as HPV) (11), in case of a further diagnosis.

Prior to this study, empirical data on CSWs in Nigeria remain scanty with only a handful of systematic reviews published to date. Most available studies are global in focus, leaving distinct regional and sub-regional patterns largely unexplored. Therefore, the present study focused on examining the cytopathology of cervicitis in CSWs in Enugu metropolis, Nigeria using an improved method of Pap smear examination (liquid-based cytology) (5) and modified Pap staining techniques (2). The objectives were to: (i) examine patterns of cervicitis infection in CSWs, (ii) determine the prevalence of CSWs living with cervicitis, and (iii) evaluate the overall burden of cervicitis on the infected individuals.

\section{MATERIALS AND METHODS}

Study population: A total of one hundred and eighteen $(n=118)$ CSWs who consented were recruited for this study. The study was conducted among an official urban population of 722,664 Southeastern Nigeria (12), between October 2014 and February 2015. Nineteen brothels within Enugu metropolis which includes brothels in settlements, markets, residential areas and busy road intersections were identified (2). Informed consent was obtained from all participating CSWs. Approval for the work was granted by Enugu State Ministry of Health, Nigeria.

Data collection: CSWs were surveyed through structured questionnaire completed on a voluntary basis and administered in vernaculars (Pidgin English) where necessary. The survey included 30 questions that offered predominantly multiplechoice options although open-ended questions were also available. Data was centered on sociodemographics: educational background, healthcare-seeking behaviors, sexual experience and history of sexually transmitted diseases (2). The survey also included a variety of issues regarding sexual practices, including the number of sexual contacts and history of current and former symptoms.

Specimen collection, preparation and processing: Qualified female medical personnel conducted the pelvic examination. Speculum was used for inspection of the external genitalia, vagina and cervix for any lesion or inflammation. Prior to sample collection, CSWs who are menstruating and those who are pregnant were excluded. Cervical smear from the endocervix was obtained by a qualified nurse using liquid-based cytology (SurePath ${ }^{\mathrm{TM}}$; BD TriPath, Burlington, NC. USA) (13, 14). The process was accomplished with a broom-like sampling device (cervix-brush) which was detached after sampling and aseptically lowered into a preservative vial. Preparation of slides for cytological examination was done using the Cytospin (IEC 61010 Thermo Scientific Cytospin 4, GMI, Inc. USA). Staining of the smear was done according to the modified Papanicolaou methods (15). Slide preparation and staining were done within 4-6 hours of sample collection. Leftover samples are refrigerated at $4^{\circ} \mathrm{C}$ after use. Thereafter, about $1.0 \mathrm{ml}$ of LBC sample was aseptically pipetted from each vial and was tested for $C$. trachomatis and $N$. gonorrhoea. 
Ligase chain reaction (LCR) (LCx- Abbott Laboratories, Chicago, Ill.) and nucleic acid amplification test (NAAT) (11) are the molecular testing methods used.

Cytopathology of cervicitis: Using the X40 objective, nucleoli and chromatin patterns are differentiated. The inflammatory process is classified as acute when $>70 \%$ of the inflammatory cells are neutrophils, as sub-acute or chronic active when $50-70 \%$ of the inflammatory cells are neutrophils and 30-50\% macrophages, and chronic when $>50 \%$ of the inflammatory cells are macrophages (13). Gynecological signs potentially indicating cervicitis are cervical discharge, pus on the cervical swab, bleeding after sampling and inflammatory cervix (16). Also, identification of 10 or more polymorphonuclear cells per oil immersion field X100 correlates strongly with mucopurulent cervicitis (5).

Additional diagnosis of importance: Excessive discharge or mucus was removed from the exocervix with a large headed swab (Copan, California) obtained for Gram stain examination, wet preparation mount and culture for sexually transmitted diseases, Trichomonas vaginalis and Candida albicans infections.

Statistical analysis: Age, sexual activities and behavioral risk factors including working duration as CSWs, commercial sex frequency and use of the condom are the independent variables used as predictors of a positive cervicitis test (17). The results were coded, double-entered and crosschecked using Microsoft Excel and FoxPro 2.6. Data were analyzed using one-way analysis of variance and Duncan post hoc test, with the statistical software GraphPad Prism version 6.1. Statistical significance was set at $\mathrm{P}<0.05$.

\section{RESULTS}

A significant rate of cervicitis was recorded in LBC specimen from a total of one hundred and eighteen $(n=118)$ CSWs. The pattern of cervicitis was evenly distributed (Table 1). Cytopathological examination of cervicitis showed a moderate infection and moderately severe to chronic inflammatory cells (Figure 1). The distribution further revealed that $7(5.9 \%)$ represent acute stage of the infection and $2(1.7 \%)$ are chronic. Also, evaluation of the overall burden of cervicitis on the individual in the illicit business also suggests that age group (15-20) years are mostly affected (Table 2). LCR and NAAT detected $C$. trachomatis DNA in 9 (LBC) samples from one hundred and eighteen $(n=118)$ CSWs tested. In disclosure, $N$. gonorrhea was not detected by either culture, LCR or NAAT in the present study. Associated pathogen (C. trachomatis) was represented in $8 / 9$ cases of cervicitis and 1/9 incident accounted for nonassociated pathogen in the study population. Although, diagnosis of importance (gram-stain, wet preparation, and culture) bared other forms of STDs. T. vaginalis and $C$. albicans infections were not detected in cervicitis group $(n=9)$. However, $(n=12)$ cases of Candidiasis and $(n=3)$ cases of $T$. vaginalis detected were observed in non-cervicitis group $(\mathrm{n}=109)$.

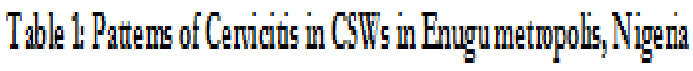

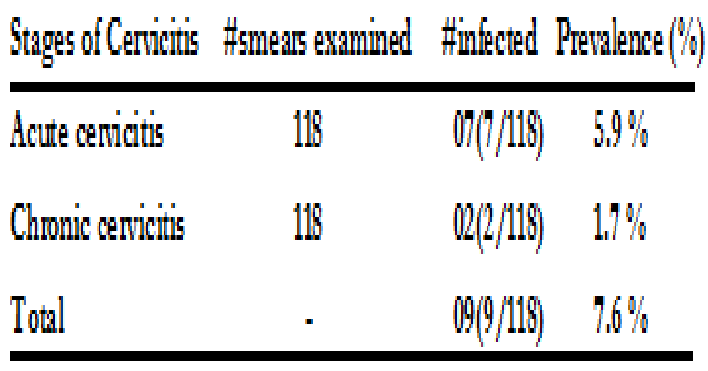

Tablez: Distribution of C. trachom atis infection in CSW's in relation to age group

\begin{tabular}{lcc}
\hline $\begin{array}{l}\text { Agegroup } \\
(\mathrm{n}=118)\end{array}$ & $\begin{array}{c}\text { \#CST/s infected } \\
(\mathrm{n}=9)\end{array}$ & $\begin{array}{c}\text { Preralence } \\
(\%)\end{array}$ \\
\hline$<14$ & $00(0.9)$ & $00.0 \%$ \\
15.20 & $05(5 / 9)$ & $53.6 \%$ \\
$21 .-25$ & $03(3 / 9)$ & $33.3 \%$ \\
26.30 & $01(1 / 9)$ & $11.1 \%$ \\
31.35 & $00(019)$ & $00.0 \%$ \\
$36-40$ & $00(0.9)$ & $00.0 \%$ \\
$>40$ & $00(0.9)$ & $00.0 \%$ \\
Total & - & $100.0 \%$ \\
\hline
\end{tabular}




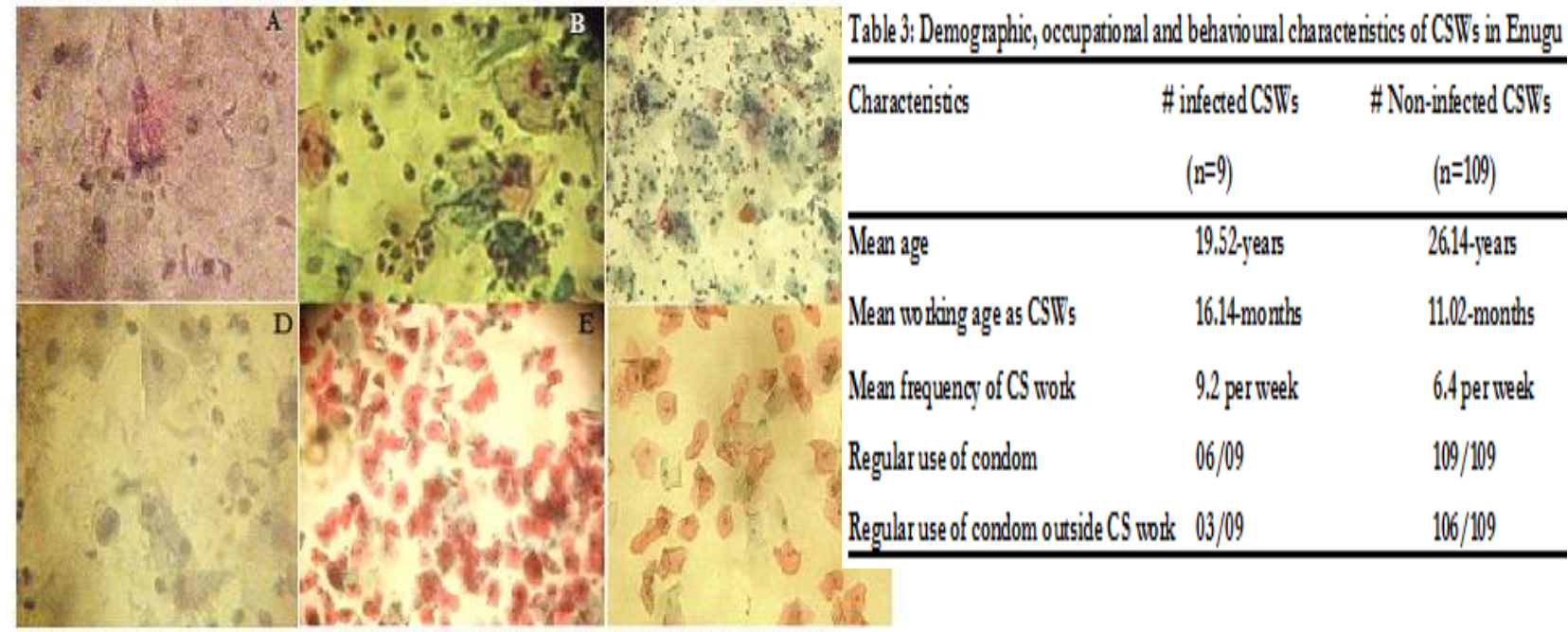

Figure 1: Cytopathology revealed the following: (A)-acute cervicitis (moderate infection Table 4: Cervicitis among CSWs in relation to age

\begin{tabular}{|c|c|c|c|c|}
\hline $\begin{array}{l}\text { of the inflammatory cells are neutrophils, (B)-moderately severe acute cervicitis, } 50-70 \% \\
\text { inflammatory cells are neutrophils and } 30-50 \% \text { are macrophages, (C)-chronic cervicitis s }\end{array}$ & Age group & $\begin{array}{l}\text { No of CSWs } \\
(\mathrm{n}=118)\end{array}$ & $\begin{array}{l}\text { No infected } \\
(\mathrm{n}=9)\end{array}$ & $\begin{array}{c}\text { Prevalence } \\
(\%)\end{array}$ \\
\hline the inflammatory cells are macrophages, (D)-chronic cervicitis, (E)-normal cervical sm & $<14$ & 00 & $00(0 / 0)$ & $0.0 \%$ \\
\hline non-infected CSW and (F)-normal cervical smear of a non-infected and non-CSW ( $E$ & $15-20$ & 56 & $05(5 / 56)$ & $8.9 \%$ \\
\hline serves as negative controls). LBC modified Papanicolaou staining method at & $21-25$ & 47 & $03(3 / 47)$ & $6.4 \%$ \\
\hline & $26-30$ & 12 & $01(1 / 12)$ & $8.3 \%$ \\
\hline Young CSWs (15-20) years were significantly & $31-35$ & 03 & $00(0 / 3)$ & $0.0 \%$ \\
\hline associated with cervicitis infection $(P=0.0322)$ & $35-40$ & 00 & $00(0 / 0$ & $0.0 \%$ \\
\hline $\begin{array}{l}\text { while the association between } C \text {. trachomatis and } \\
\text { cervicitis infection were statistically significant }\end{array}$ & $>40$ & 00 & $00(0 / 0)$ & $0.0 \%$ \\
\hline$(P=0.0221)$. The distribution, prevalence $(7.6 \%)$ & Total & 118 & 09 & $100 \%$ \\
\hline
\end{tabular}

and frequencies of cervicitis by behavioral characteristics, age, and tribe, are presented in (Table $3 \& 4)$. The highest influx of CSWs (15$20)$ years had an infection rate $5(8.9 \%)$. Closely followed by 26-30years $1(8.3 \%)$ and $3(6.4 \%)$ which accounted for 21-25years of the study population.

Data obtained through survey exercise revealed an average age of 21.5 years (range 1726) for commercial sex, mean number of years of formal education (4.1years) and median 4.7 years (range 1-10). A woofing sum, (42\%) of CSWs, had no formal education; $46 \%$ had six years of formal education while $12 \%$ are junior secondary school dropouts. Furthermore, about $55 \%$ of the study population is of the polygamous homes while $35 \%$ accounted for are of single-parent.

\section{DISCUSSION}

This study did not make an in-depth molecular analysis of cervicitis, but it relatively engrossed the confirmation of the presence of pathogens as a primary contributory agent to the etiology of cervicitis in CSWs. It further gives an insight into the way and manner by which cervicitis infection is acquired by CSWs in a famous ancient coal city (Enugu), Nigeria. To this end, sample collection, processing and preparation of smears by $\mathrm{LBC}$ are made easy and more definitive for accurate cytologic screening. In addition, features of abnormal cells are detected more precisely and efficiently. Again, by LBC, organisms (sexually transmitted disease pathogens) and DNA are well preserved for future analysis and further test procedures (11). This preservative quality presents an opportunity to detect other infections that may be present in the cervix and vagina. This is due to 
the fact that the DNA from a cervical sample Pathogens tested in our study (C. trachomatis and $N$. gonorrhoea) are in agreement with major causes of cervicitis most commonly reported in United States (11) and other parts of the world (16).

Against this background, the previous works on cytopathology of cervicitis, patterns, prevalence, and the burden of cervicitis in CSWs are not so common (2). To the best of our knowledge, there are limited research attempts on the prevailing subject matter. Regardless of the limited work done, our findings support the disclosure that cervicitis infection is more frequent in CSWs with a little or no formal education. It further suggests that it may be connected to the health seeking behavior or lack of condom use. This observation has been reported $(2,15)$. Cervicitis appears to be more common in CSWs that are involved in the sex business for more than 12 months. It might relate to factors similar to lack of acquired immunity to the causative pathogen (C. trachomatis). In the present study, cervicitis infection appears more frequent in young CSWs between (15-20) years. Similar observations were earlier documented in Benin City, Nigeria (2) and Accra, Ghana (16). Little or no formal education reported previously by a majority of the respondents (CSWs) in Benin City and Accra metropolis are absolute views to reckon with in our study. Associations are found between $C$. trachomatis and the presence of the four signs thought to be indicative of cervicitis. This is in accordance with other similar findings (16) that confirm the importance of the four signs of cervicitis detected in this study. It is pertinent to observe that agents of urethritis such as $N$. gonorrhoea and C trachomatis causes cervicitis in women. This report agrees with Holmes and Stamm (17), going by the level of correlation between $C$. trachomatis and the signs of cervicitis earlier documented (17).

The present study agrees with the claim that endocervicitis is the most common presentation of chlamydial infection $(11,16)$. Endocervicitis is a known factor when dealing with chlamydial infection and has been reported (18). Chlamydiainfected CSWs with excessive or blood stained discharge are observed critically as the most common complaint in this study. It thereby signals the presence of endocervical infection which appears to be stable at room temperature (11). exacerbates into cervicitis $(19,20)$. Our findings are in line with Mak (5), looking at the relationship between chlamydial infection, and working duration as a CSW, frequency of commercial sex and condom use. It is understandable to have reporting errors when answering questions on sensitive issues. Matters relating to sex rate, and work duration as a sex worker may provide errors due to memory lapse. These errors could easily set in when providing nebulous information and may not be readily substantiated (16). It may also be due in parts that interpretation of the regular use of the condom varied among subjects thereby perplexing the results. Though, a large number of CSWs are not addressed in this study unlike the study in Accra, Ghana (16).

In conclusion, $55.6 \%$ of the infected CSWs in this study are below the age of consent, which portrays that teenagers are of a more vulnerable group. There was acute cervicitis preponderance of $4: 1$ as against chronic cervicitis, which again is predominant among the adolescents. Prevalence of cervicitis could be considered as high; it is likely to be underestimated due to the migratory nature of the CSWs from one area of the city to another. However, the actual picture of CSWs living with cervicitis infection in this part of the world (Enugu, Nigeria) may not have been accurately represented in this study. It portrays an impending danger for the social and economic future of our country (Nigeria). Our findings suggest that there are teenage CSWs living with cervicitis in the study settings. Acute cervicitis is prevalent, and $C$. trachomatis infection is the most frequent etiologic agent of cervicitis in this study. Further study should attempt to investigate the LBC smears obtained from CSWs by polymerase chain reaction (PCR). It may help in the DNA detection of a broad range of etiologic agents e.g. cytomegalovirus (CMV), herpes simplex virus (HSV) type 1 and 2, and human papillomavirus (HPV).

\section{ACKNOWLEDGEMENT}

We appreciate the enormous support of commercial sex workers who participated in this study and the State Ministry of Health, Enugu for approval to carry out this work. We are grateful to 
the management and staffs (Gynecologist, Nurses, Pathologist, and Scientist) of the University of Nigeria, UNTH, Enugu and Specialist Hospital, Parklane for their kind support in championing this work.

\section{REFERENCES}

1. Fiona S, Matthew FC, Ntaganira I, Antonio G, Frank L, Ying-Ru L. Socio-Demographic Characteristics and Behavioral Risk Factors of Female Sex Workers in Sub-Saharan Africa: A Systematic Review. AIDS Behav, 2011; 15:1309-1318.

2. Odigie BE, Odega KI. Cervicitis amongst teenage sex workers in Benin metropolis, Nigeria: the viewpoint of the cytologist. Afri $J$ Cell Path, 2013; 1: 34-39.

3. Marrazzo JM. Mucopurulent cervicitis: no longer ignored, but still misunderstood. Infect Dis Clin North Am, 2005; 19:333-349.

4. Johnson LF, Lewis DA. The effect of the genital tract infections on HIV-1 shedding in the genital tract: a systematic review and meta-analysis. Sex Transm Dis, 2008; 35:9-46.

5. Mak KH. Genital chlamydia trachomatis infection in commercial sex workers attending a sexually transmitted disease clinic in Hong Kong. Hong Kong Dermatology \& Venereology Bulletin, 2000; 8: 4-8.

6. Tanaka M, Nakayama H, Sakumoto M. Reduced chlamydial infection and gonorrhea among commercial sex workers in Fukuoka City, Japan. Int J Urol, 1998; 5: 471-475.

7. Vandepitte J, Lyerla R, Dallabetta G, Crabbe F, Alary M, Buve A. Estimates of the number of female sex workers in different regions of the world. Sex Transm Infect, 2006; 82:18-25.

8. Cwikel JG, Lazer T, Press F, Lazer S. Sexually transmissible infections among female sex workers: an international review with an emphasis on hard-to-access populations. Sex Health, 2008; 5:9-16.

9. Talbott JR. Size matters: the number of prostitutes and the global HIV/AIDS pandemic. PLOS One, 2007; 2:1-8.

10. Rekart ML. Sex-work harm reduction. Lancet, 2005; 366: 2123-2134.

11. Koumans EH, Carolyn MB, Lauri EM, ElizabethR U, Antonya P, Mary KS, John RP.
Comparison of Methods for Detection of Chlamydia trachomatis and Neisseria gonorrhoeae Using Commercially Available Nucleic Acid Amplification Tests and a Liquid Pap Smear Medium. J Clin Microbiol, 2003, 41(4):1507-1511.

12. Nigeria Population and Census Board. Population by state and sex: population.gov.ng, 2006

13. Edmund SC, Barbara SD. Cytology: Diagnostic Principles and Clinical Correlates. 3rd ed. Philadelphia, Saunders Elsevier, 2008:197-206.

14. Koss LG. Diagnostic cytology and its histopathology bases. 1st ed. Philadelphia, Lippincott JB, 2005: 70-73.

15. Odigie BE, Obaseki DE. Conventional Pap technique (CPT) in comparison to the modified emergency method (MEM) in cytodiagnosis of Pap smear and fine needle aspiration cytology specimens. Ann Biomed Sci, 2014; 13: 23-30.

16. Pe'pin J, Labbe' AC, Khonde $\mathrm{N}$ et al. Mycoplasma genitalium: an organism commonly associated with cervicitis among West African sex workers. Sex Transm Infect, 2005; 81:67-72.

17. Holmes KK, Stamm WE. Lower genital tract infection syndromes in women. In: Holmes KK, Sparling PF, Mardh PA, et al. ed. Sexually transmitted diseases. New York McGraw-Hill, 1999:761-781.

18. Casin I, Vexiau-Robert D, De La Salmonie`re P, Eche A, Grandry B, Janier M. High prevalence of Mycoplasma genitalium in the lower genitourinary tract of women attending a sexually transmitted disease clinic in Paris, France. Sex Transm Dis, 2002; 29: 353-359.

19. Shahmanesh M, Patel V, Mabey D, Cowan F. Effectiveness of interventions for the prevention of HIV and other sexually transmitted infections in female sex workers in resource poor setting: a systematic review. Trop Med Int Health, 2008; 13:659-679.

20. Lim WL, Chan YY. A preliminary epidemiological assessment of Chlamydia trachomatis infection in Hong Kong. Hong Kong Practitioner, 1999; 13:1679-83. 